\title{
PENERAPAN METODE INKUIRI DENGAN PENDEKATAN TANOSHII JUGYOU UNTUK MEMPERBAIKI KONSEP OPERASI BILANGAN
}

\author{
Dyah Ayu Sulistyaning Cipta \\ IKIP Budi Utomo Malang \\ dyahayu.esce@gmail.com
}

\begin{abstract}
Abstrak
Tujuan penelitian ini adalah mendeskripsikan desain pembelajaran metode inkuiri dengan pendekatan Tanoshii Jugyou agar mahasiswa yang menempuh matakuliah Telaah Matematika SD memahami konsep operasi pada bilangan bulat dan pecahan. Penelitian ini merupakan penelitian kualitatif yang menggambarkan bagaimana pembelajaran metode inkuiri dengan pendekatan Tanoshii Jugyou diterapkan di dalam kelas. Hasil penelitian menyimpulkan bahwa desain pembelajaran metode inkuiri dengan pendekatan Tanoshii Jugyou untuk konsep operasi pada bilangan bulat dan pecahan adalah: 1) orientasi untuk menciptakan suasana pembelajaran yang lebih responsif, 2) merumuskan masalah untuk membawa mahasiswa ke sebuah persoalan yang harus dipecahkan, 3) membuat hipotesis, 4) mengumpulkan data untuk menjaring informasi yang diperlukan yang nantinya digunakan untuk menguji hipotessis yang telah diajukan, 5) menguji hipotesis. Pada pengujian hipotesis inilah letak penekanan pembelejaran ini agar mahasiswa dapat benar-benar memahami konsep operasi pada bilangan bulat dan pecahan. Seluruh kegiatan pembelajaran dilakukan dengan membuat suasana kelas sangat menyenangkan. Mahasiswa dipersilakan mengeluarkan ide kreatifnya tanpa rasa takut sedikitpun.
\end{abstract}

Kata kunci: inkuiri, tanoshii jugyou, operasi bilangan bulat, operasi bilangan pecahan

\begin{abstract}
Tujuan penelitian ini adalah mendeskripsikan desain pembelajaran metode inkuiri dengan pendekatan Tanoshii Jugyou agar mahasiswa yang menempuh matakuliah Telaah Matematika SD memahami konsep operasi pada bilangan bulat dan pecahan. Penelitian ini merupakan penelitian kualitatif yang menggambarkan bagaimana pembelajaran metode inkuiri dengan pendekatan Tanoshii Jugyou diterapkan di dalam kelas. Hasil penelitian menyimpulkan bahwa desain pembelajaran metode inkuiri dengan pendekatan Tanoshii Jugyou untuk konsep operasi pada bilangan bulat dan pecahan adalah: 1) orientasi untuk menciptakan suasana pembelajaran yang lebih responsif, 2) merumuskan masalah untuk membawa mahasiswa ke sebuah persoalan yang harus dipecahkan, 3) membuat hipotesis, 4) mengumpulkan data untuk menjaring informasi yang diperlukan yang nantinya digunakan untuk menguji hipotessis yang telah diajukan, 5) menguji hipotesis. Pada pengujian hipotesis inilah letak penekanan
\end{abstract}


pembelejaran ini agar mahasiswa dapat benar-benar memahami konsep operasi pada bilangan bulat dan pecahan. Seluruh kegiatan pembelajaran dilakukan dengan membuat suasana kelas sangat menyenangkan. Mahasiswa dipersilakan mengeluarkan ide kreatifnya tanpa rasa takut sedikitpun.

Key words: inquiry, tahoshii jugyou, integer operation, fraction operation

\section{PENDAHULUAN}

Diperlukan suatu usaha tertentu untuk memahamkan konsep operasi bilangan bulat dan pecahan yang bersifat abstrak. Tanpa pemahaman konseptual yang kuat tentang pecahan, perhitungan dengan pecahan menjadi aturan tanpa logika (Van De Walle, 2008: 35). Melalui hasil observasi dengan memberikan pertanyaan sederhana berupa satu soal perkalian bilangan bulat yang diberikan kepada 33 mahasiswa kelas 2014 F Pendidikan Matematika IKIP Budi Utomo Malang, tidak satupun diantara mereka yang mampu menjelaskan secara konsep, dari mana mereka mendapatkan jawabannya. Mereka hanya bisa menjawab bahwa $-2 \times$ 3 adalah -6 , tanpa tahu darimana ia mendapatkan -6 . Yang mereka tahu hanyalah bahwa jika negatif dikali positif maka akan memberikan hasil negatif.

Jawaban tersebut tidak salah, namun terasa begitu memprihatinkan jika sebagai mahasiswa program studi pendidikan matematika yang kelak akan menjadi guru matematika tidak memahami konsep matematika dengan benar. Jika hal ini terus dibiarkan berlanjut, maka pembelajaran matematika hanya akan terhenti pada penghafalan teori belaka tanpa suatu logika.

Setelah menelusuri lebih lanjut dengan melakukan investigasi kepada 33 mahasiswa kelas $2014 \mathrm{~F}$ tersebut, didapati bahwa 16 mahasiswa diantara mereka tidak pernah terbesit bahwa hal tersebut perlu dipertanyakan. Sebanyak 10 mahasiswa mengaku mendapatkan informasi bahwa bilangan bulat negatif yang dikalikan dengan bilangan bulat positif dan menghasilkan bilangan bulat negatif adalah suatu postulat yang tidak perlu dipertanyakan lagi asal muasalnya. Kemudian sebanyak 7 mahasiswa mengaku pernah menggali informasi tersebut namun hingga saat ini belum mendapatkan jawabannya.

Pembelajaran yang mereka dapatkan selama ini, dari jenjang SD, SMP, hingga SMA, operasi bilangan bulat dan pecahan selalu disajikan dengan menjejali rumusan-rumusan matematika tanpa dijelaskan dari mana datangnya rumus tersebut. Sebagai contoh, ketika berhadapan dengan pengurangan bilangan negatif, $a-$ $(-b)$, guru langsung meyakinkan kepada siswa bahwa $a-(-b)=$ 
$a+b$. Demikian pula dengan pecahan $\frac{a}{b} \div \frac{c}{d}$, setelah mengalikan dengan sekawannya didapat $\frac{a}{b} \div$ $\frac{c}{d}=\frac{a}{b} \times \frac{d}{c}$. Tanpa ada penjelasan mengapa demikian, tanpa memahami konsep pengurangan bilangan negatif, tanpa memahami konsep pembagian bilangan pecahan, mereka diminta menghafal rumusan-rumusan matematika tersebut.

Berakar masalah konsep bilangan tersebut, maka dalam hal ini yang harus diperbaiki adalah cara pembelajaran matematika, cara memotivasi mahasiswa, dan cara membangkitkan ide kreatif mahasiswa. Karena konsep bilangan ini seharusnya telah mereka miliki sejak kelas IV SD, maka itu berarti telah selama hampir sepuluh tahun aturanaturan yang tidak berdasar pada konsep itu berakar begitu kuat dalam otak mereka. Setelah sekian lamanya aturan-aturan tersebut berakar, bukan perkara yang mudah untuk memperbaikinya.

Untuk memperbaiki konsep bilangan tersebut tidak cukup hanya dengan pembelajaran yang disajikan dengan ceramah saja. Dalam hal ini diperlukan suatu pembelajaran yang menantang dan mengalahkan aturan-aturan yang telah lama bercokol dalam otak mereka. Model pembelajaran yang dianggap cocok untuk mengatasi permasalahan ini adalah model pembelajaran inkuiri. Menurut
Arsa (2015: 20) pembelajaran inquiri adalah rangkaian kegiatan pembelajaran yang menekankan pada proses berpikir secara kritis dan analitis untuk mencari dan menemukan sendiri jawaban dari suatu masalah yang dipertanyakan. Selanjutnya, agar pembelajaran tidak membosankan dan mahasiswa terus bersemangat untuk menemukan konsep bilangan, pembelajaran dikemas dengan pendekatan Tanoshii Jugyou. Tanoshii Jugyou merupakan sebuah istilah yang digunakan dalam kurikulum pembelajaran di Jepang yang mengandung arti bahwa kelas harus menyenangkan (Hayati, 2015).

\section{METODE PENELITIAN}

Penelitian ini dilakukan di kelas F Prodi pendidikan Matematika IKIP Budi Utomo Malang. Penelitian ini menekankan makna pada pemahaman konsep bilangan sebagai hasil penelitian dengan menjadikan peneliti sebagai instrumen kunci. Dengan demikian, maka jenis penelitian yang digunakan adalah penelitian kualitatif. Sugiyono (2016: 15) menyebutkan bahwa metode penelitian kualitatif adalah penelitian yang berlandaskan pada filsafat postpositifme, digunakan untuk meneliti pada kondisi obyek yang alamiah, di mana peneliti sebagai instrumen kunci, 
pengambilan sampel sumber data dilakukan secara purposive dan snowbaal, twknik pengumpulan dengan triangulasi, analisis data bersifat indukif, dan hasil penelitian lebih menekankan makna dari pada generalisasi.

\section{HASIL DAN PEMBAHASAN}

Desain Pembelajaran Metode Inkuiri dengan Pendekatan Tanoshii Jugyou pada Operasi Bilangan Bulat dalam Matakuliah Telaah Matematika SD

Kelas pada pelakasanaan pembelajaran metode inkuiri dengan pendekatan tanoshii jugyou dirancang secara berkelompok agar mempermudah memantau aktivitas mahasiswa selama proses pembelajaran. Diskusi kelompok yang dipilih pada proses pembelajaran ini adalah teknik Buzz Group, yaitu dengan membagi kelas menjadi dua sampai delapan kelompok kecil, kemudian kelompok kecil ini diminta melaporkan hasil diskusinya kepada kelas (Roestiyah, 2008: 9).

Berikut adalah langkah-langkah pembelajaran metode inkuiri dengan pendekatan tanoshii jugyou pada Operasi Bilangan Bulat dalam Matakuliah Telaah Matematika SD.

\section{Orientasi}

Tahapan ini merupakan sebuah langkah untuk menciptakan suasana pembelajaran yang lebih responsif. Mahasiswa harus dikondisikan agar siap dalam melaksanakan kegiatan pembelajaran. Membangun kesiapan mahasiswa dapat dilakukan dengan: (a) menjelaskan tujuan pembelajaran, yaitu mahasiswa dapat memahami konsep operasi pada bilangan bulat dan pecahan serta dapat melakukan praktik mengajar untuk siswa SD, (b) menjelaskan berbagai pokok kegiatan, yaitu pemanfaatan media sederhana untuk mencapai tujuan pembelajaran, dan (c) menjelaskan betapa pentingnya topik dan tujuan belajar ini, agar kelak siswanya tidak hanya menerima sebuah aturan dalam operasi bilangan bulat tanpa suatu logika seperti yang telah ia terima dahulu.

\section{Merumuskan Masalah}

Merumuskan masalah ini adalah langkah yang akan membawa mahasiswa ke sebubuah persoalan yang harus dipecahkan. Jadi persoalan tersebut disajikan dengan menarik agar lebih menantang mahasiswa untuk memecahkan teka-teki yang ada. Adapun konsep teka-teki tersebut haruslah mengandung konsep jelas sehingga bisa ditemukan atau dicari penyelesaiannya.

\section{Merumuskan Hipotesis}


Hipotesis merupakan jawaban yang sifatnya sementara terhadap masalah yang masih praduga karena masih harus diverifikasi (Kurniawan, 2015). Artinya, hipotesis masih perlu diuji kebenarannya. Pada tahapan ini, peneliti mendorong mahasiswa untuk merumuskan jawaban sementara.

Hipotesis yang dirumuskan adalah sebagai berikut:

Operasi penjumlahan pada bilangan bulat

$$
a+(-b)=a-b \quad-a+
$$

$b=b-a, \quad-a+(-b)=-(a+$

b)

Operasi pengurangan pada bilangan bulat

$$
a-(-b)=a+b, \quad-a-
$$

$b=-(a+b), \quad-a-(-b)=$

$-a+b$

Operasi perkalian pada bilangan bulat

$$
\begin{aligned}
& a \times(-b)=-(a b) \\
& (-a) \times b=-(a b) \\
& (-a) \times(-b)=a b
\end{aligned}
$$

Operasi pembagian pada bilangan bulat

$$
\frac{-a}{b}=-\left(\frac{a}{b}\right) \frac{a}{-b}=-\left(\frac{a}{b}\right) \quad \frac{-a}{-b}=\frac{a}{b}
$$

\section{Mengumpulkan Data}

Tahapan ini dilakukan untuk menjaring informasi yang diperlukan yang nantinya digunakan untuk menguji hipotesis yang telah diajukan. Pada tahapan pengumpulan data ini mahasiswa diarahkan untuk mengingat kembali.

Sifat operasi penjumlahan pada bilangan bulat: (1) sifat komutatif $a+b=b+a$;(2) sifat asosiatif $a+(b+c)=(a+b)+c$; adanya elemen identitas, yaitu 0 , sehingga $a+0=a$; (4) adanya elemen invers, yaitu $-a$ sehingga $a+(-a)=0$.

Sifat operasi perkalian pada bilangan bulat: (1) sifat komutatif, $a \times b=b \times a$; (2) sifat asosiatif, (3) $a \times(b \times c)=(a \times b) \times c$; adanya elemen identitas, yaitu 0 , sehingga $a \times 1=a$; (5) adanya elemen invers, yaitu $-a$ sehingga $a \times \frac{1}{a}=1$.

Sifat distributif penjumlahan terhadap perkalian: (1) distributif kiri, $\quad a \times(b+c)=(a \times b)+$ $(a \times c)$; dan (2) distributif kanan, $(a+b) \times c=(a \times c)+(b \times c)$. Konsep perkalian bilangan asli $a \times$ $b$ mengandung pengertian bahwa

$$
\underbrace{b+b+b+\cdots+b}_{a}=a b
$$

Konsep pembagian berawal dari perkalian $\ldots \times a=b$ mengartikan berapa banyak himpunan $a$ menghasilkan himpunan $b$ ? Atau dalam simbol pembagian dapat dituliskan $\frac{b}{a}=\cdots$.

\section{Menguji Hipotesis}

Untuk menguji hipotesis, peneliti meminta mahasiswa bergabung bersama kelompok yang telah ditentukan sebelumnya. Berikutnya, dengan berbekal model yang telah disiapkan masing-masing kelompok, mahasiswa mengerjakan LKM yang telah disiapkan peneliti. Model yang telah disiapkan 
mahasiswa adalah model untuk pencacah positif dan pencacah negatif. Sebagai contoh, mahasiswa menyiapkan sejumlah sedotan biru sebagai pencacah positif dan sedotan kuning sebagai pencacah negatif. Contoh lain, mahasiswa menyiapkan kertas berbentuk apel merah sebagai pencacah positif dan apel hijau sebagai pencacah negatif.

LKM yang diberikan peneliti adalah untuk menguji hipotesis berdasarkan data yang telah dikumpulkan. LKM ini mengarahkan mahasiswa untuk memahami konsep operasi bilangan bulat dan pecahan. Selama mahasiswa mengerjakan LKM secara berkelompok, peneliti mempersilahkan mahasiswa untuk menyalakan musik jika berkenan.

Sebagai contoh dalam langkah ini, untuk memahami konsep penjumlahan bilangan bulat positif dan negatif diawali dengan petunjuk berikut.

Siapkan model pencacah untuk mewakili bilangan bulat positif dan bilangan bulat negatif, misalkan daun merah sebagai pencacah positif dan daun hijau sebagai pencacah negatif.

+ berarti menambahkan sesuatu ke dalam himpunan.

Selanjutnya, dengan berbekal kedua petunjuk tersebut, ambil permisalan untuk menjumlahkan bilangan positif dan negatif, misalnya $3+(-5)$
$3+(-5)$ artinya adalah menambahkan himpunan berisi 5 pencacah negatif pada himpunan berisi 3 pencacah positif

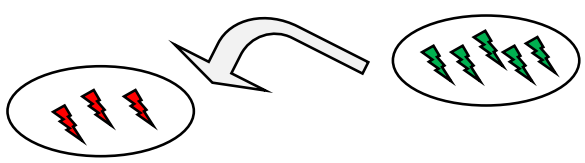

Sehingga di dalam himpunan berisi 3 daun merah dan 5 daun hijau

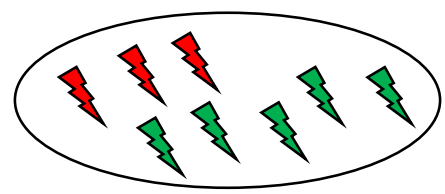

Pada proses pengumpulan data didapati bahwa $a+(-a)=0$. Artinya, ketika satu daun merah dipasangkan dengan satu daun hijau maka bernilai nol.

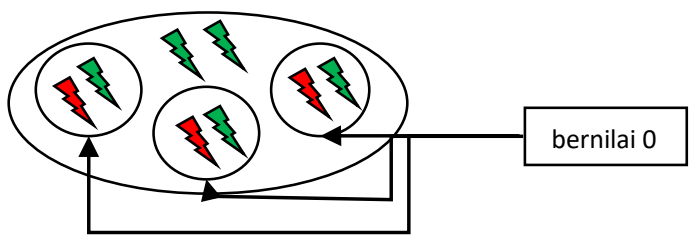

Dengan demikian, dapat disimpulkan bahwa pada himpunan tersebut terdapat 2 daun hijau sebagai pencacah negatif yang bernilai -2 . Sehingga $3+(-5)=-2$

\section{Menarik Kesimpulan}

Tahapan akhir dari metode inkuiri ini adalah menyimpulkan sebuah konsep setelah beberapa kali melakukan percobaan dalam pengujian hipotesis.

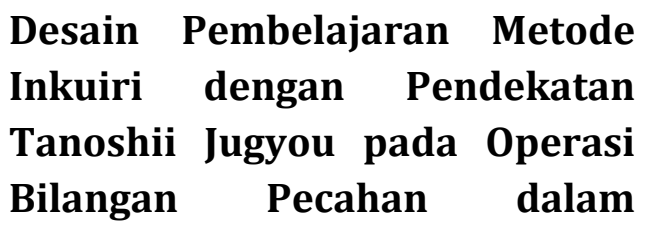




\section{Matakuliah Telaah Matematika} SD

Berikut adalah langkah-langkah pembelajaran metode inkuiri dengan pendekatan tanoshii jugyou pada Operasi Bilangan Pecahan dalam Matakuliah Telaah Matematika SD

\section{Orientasi}

Isi dari tahapan ini sama dengan tahapan dalam orientasi pada pembelajaran operasi bilangan bulat.

\section{Merumuskan Masalah}

Tahapan ini juga berisi sama dengan tahapan dalam merumuskan masalah pada pembelajaran operasi bilangan bulat.

\section{Merumuskan Hipotesis}

Pada tahapan ini, peneliti mendorong mahasiswa untuk merumuskan jawaban sementara. Hipotesis yang dirumuskan adalah sebagai berikut:

Operasi penjumlahan pada pecahan

$\frac{a}{b}+\frac{c}{d}=\frac{a d+c b}{b d}$

Operasi pengurangan pada pecahan

$\frac{a}{b}-\frac{c}{d}=\frac{a d-c b}{b d}$

Operasi perkalian pada pecahan $\frac{a}{b} \times \frac{c}{d}=\frac{a c}{b d}$

Operasi pembagian pada pecahan

$\frac{a}{b} \div \frac{c}{d}=\frac{a}{b} \times \frac{d}{c}$
Pada tahapan pengumpulan data ini mahasiswa diarahkan untuk mengingat kembali tentang pengertian pecahan dan pecahan senilai.

\section{Menguji Hipotesis}

Berikut adalah contoh proses memahami konsep operasi penjumlahan pada pecahan. Misalkan dalam menghitung $\frac{2}{3}+\frac{1}{4}$. Pecahan $\frac{2}{3}$ dapat diilustrasikan seperti berikut

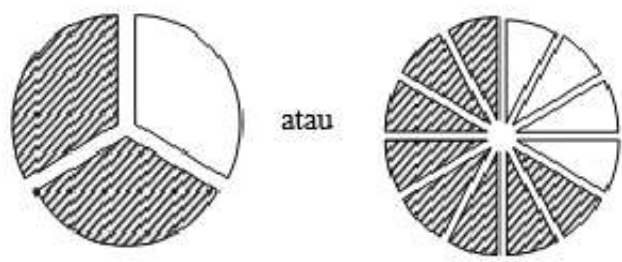

Sedangkan $\frac{1}{4}$ dapat diilustrasikan sebagai berikut.

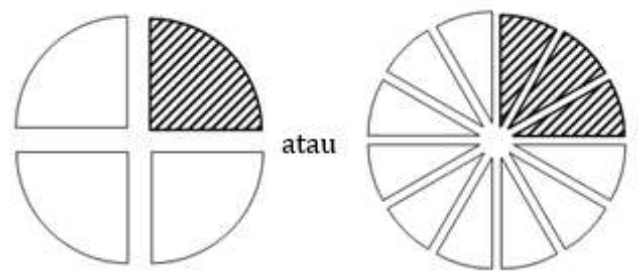

Jika ilustrasi pecahan $\frac{1}{4}$ ditambahkan pada pecahan $\frac{2}{3}$, maka diilustrasikan sebagai berikut.

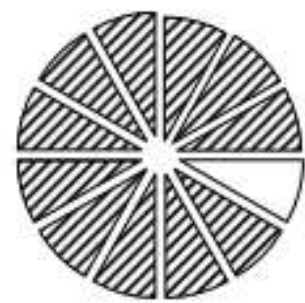

Ilustrasi pecahan tersebut adalah $\frac{11}{12}$. Dengan demikian, maka $\frac{2}{3}+\frac{1}{4}=$ $\frac{11}{12}$. 


\section{Menarik Kesimpulan}

Tahapan akhir dari metode inkuiri ini adalah menyimpulkan sebuah konsep setelah beberapa kali melakukan percobaan dalam pengujian hipotesis.

\section{KESIMPULAN DAN SARAN}

Desain pembelajaran metode inkuiri dengan pendekatan Tanoshii Jugyou untuk konsep operasi pada bilangan bulat dan pecahan adalah: 1) orientasi untuk menciptakan suasana pembelajaran yang lebih responsif, 2) merumuskan masalah untuk membawa mahasiswa ke sebuah persoalan yang harus dipecahkan, 3) membuat hipotesis, 4) mengumpulkan data untuk menjaring informasi yang diperlukan yang nantinya digunakan untuk menguji hipotessis yang telah diajukan, dan 5) menguji hipotesis. Pada pengujian hipotesis inilah letak penekanan pembelejaran ini agar mahasiswa dapat benar-benar memahami konsep operasi pada bilangan bulat dan pecahan. Seluruh kegiatan pembelajaran dilakukan dengan membuat suasana kelas sangat menyenangkan. Mahasiswa dipersilakan mengeluarkan ide kreatifnya tanpa rasa takut sedikitpun. Bagi dosen/guru yang tertarik untuk melakukan pembelajaran dengan menggunakan metode inkuiri dengan pendekatan Tanoshii Jugyou untuk konsep operasi pada bilangan bulat dan pecahan, disarankan memberikan waktu yang cukup bagi mahasiswa/siswa dalam menemukan dan memahami konsep operasi bilangan bulat dan pecahan. Berikan ruang seluasluasnya pada mahasiswa/siswa untuk mengemukakan ide kreatifnya dalam menemukan dan memahami konsep bilangan tersebut.

\section{DAFTAR PUSTAKA}

Arsa, I Putu Suka. 2015. Belajar dan Pembelajaran: Strategi Belajar yang Menyenangkan. Yogyakarta: Media Akademi.

Hayati, Rahmatul. 2015. Pembelajaran Matematika di Jepang. (online), (http://yati341.blogspot.co. id/2015/05/pembelajaranmatematika-di-jepang.html, diakses 18 Februari 2016).

Kurniawan, Aris. 2015. Pengertian Hipotesis. (online), (http://www.gurupendidik an.com/5-pengertianhipotesis-menurut-paraahli-lengkap/, diakses 26 Maret 2016).

Roestiyah. 2008. Strategi Belajar Mengajar: Salah Satu Unsur Pelaksanaan Strategi Belajar Mengajar: Teknik Penyajian. Cetakan ke-7. Jakarta: Rineka Cipta.

Sugiyono. 2016. Metode Penelitian Pendidikan: Pendekatan Kuantitatif, Kualitatif, dan $R \& D$. Bandung: Alfabeta 
Cipta, Dyah Ayu Sulistyaning

Penerapan Metode Inkuiri dengan Pendekatan Tanoshii Jugyou untuk Memperbaiki Konsep Operasi Bilangan

Van de Walle, John A. 2008. Matematika Sekolah Dasar dan Menengah Jilid 2. Edisi Keenam. (Suyono.Terj.).

Jakarta: Erlangga. 